\title{
Availability of plant nutrients and pollutants in the young soils of Surtsey compared to the older Heimaey and Elliðaey volcanic islands
}

\author{
BJARNI D. SIGURDSSON ${ }^{1}$ AND NIKI I.W. LEBLANS ${ }^{2}$ \\ ${ }^{1}$ Agricultural University of Iceland, Hvanneyri 311 Borgarnes, Iceland (bjarni@1bhi.is) \\ ${ }^{2}$ Climate Impact Research Centre, Umeå University, Sweden
}

\begin{abstract}
Surtsey and the older islands in the Vestmannaeyjar archipelago offer a unique possibility to study how sub-Arctic ecosystems develop from unvegetated mineral substrate that lacks soil cover to grasslands with thick Brown Andosol soils. The present study was carried out on Surtsey, Heimaey and Elliðaey in 2013 and involved an incubation of resin membranes in the $0-10 \mathrm{~cm}$ topsoil layer in different ecosystems, which were either inside or outside seabird colonies. We compared the effects of seabird presence on soil nutrient availability as well as the importance of time for soil development (at least ca.1600 years vs. 50 years). Further we looked for build-up of $\mathrm{Cd}$ and $\mathrm{Pb}$ within the seabird colonies. Seabird presence enhanced the availability of most nutrients ( $\mathrm{N}, \mathrm{P}, \mathrm{K}, \mathrm{Mg}, \mathrm{Ca}, \mathrm{S}, \mathrm{Fe}, \mathrm{Mn}$ and $\mathrm{Zn}$ ) except $\mathrm{B}$ and $\mathrm{Cu}$, irrespective of the age of the islands. Soil age was also a significant factor for nutrient availability for all macro- and micronutrients except $\mathrm{B}$. Nutrient ratios indicated that $\mathrm{N}$ was the most limiting nutrient in all ecosystems, except in the thicker tephra soils on Surtsey where low P availability may lead to co-limitation. The role of P in ecosystem function on Surtesy warrants a futher study. No accumulation of $\mathrm{Cd}$ and $\mathrm{Pb}$ was found within the seabird colonies.
\end{abstract}

\section{INTRODUCTION}

Primary succession, the chain of processes in which an ecosystem develops on an unvegetated substrate that lacks a developed soil (Walker \& Del Moral 2003), is a complex process that depends on the interplay of numerous factors, both biotic and abiotic. Surtsey and the older islands of the Vestmannaeyjar archepelago offer a unique possibility to study some of these factors (cf. Magnusson et al. 2014, Leblans et al. 2017).

Most studies on Surtsey have focused on community changes in flora, fauna and microbes (e.g. Magnusson et al. 2014, Ilieva-
Makulec et al. 2015, Marteinsson et al. 2015) and only few on the underlying carbon and nitrogen processes and $\mathrm{C}$ and $\mathrm{N}$ accumulation (Sigurdsson \& Magnusson 2010, Stefánsdóttir et al. 2014, Leblans et al. 2014, 2017, Aerts et al. 2020). From these studies, it is clear that the establishment of a seabird colony on Surtsey in 1986 has had a large impact on vegetation succession and ecosystem processes. Most studies so far have only focused on the $\mathrm{N}$ inputs as the most imporatant driver for ecosystem changes, and assumed that other nutrients would not be limiting. Another article in this issue 


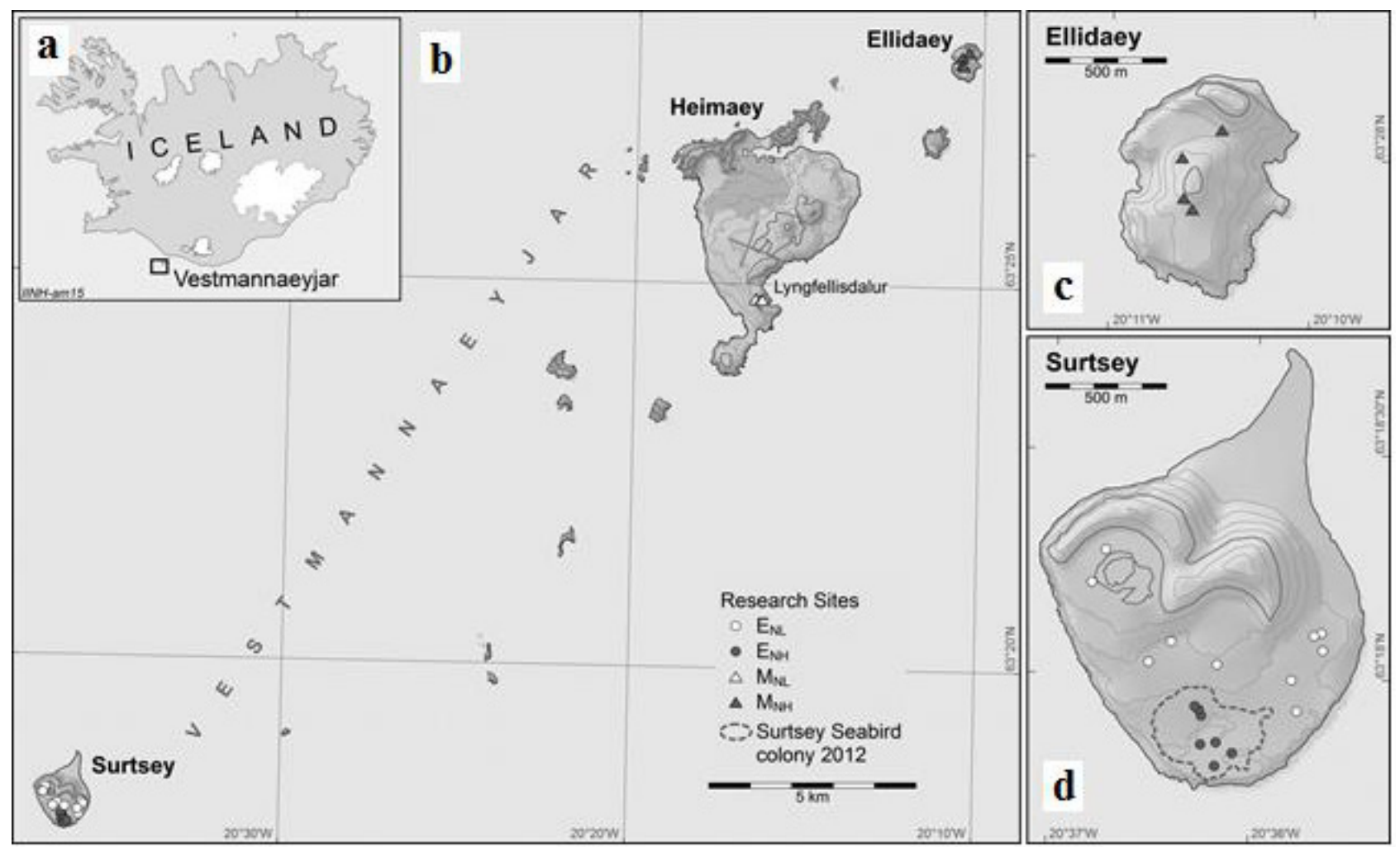

Figure 1. (a) and (b) Location of the Vestmannaeyjar archipelago including the three study islands, Surtsey, Heimaey and Elliðaey, (c) and (d) show the islands Elliðaey and Surstey in more detail. Circles show the permanent plots at early soil developmental stage under low (०) and high $(\bullet)$ inputs from seabirds within the seagull colony indicated by a dotted line. Triangles show the plots at sites with mature soils under low $(\Delta)$ and high $(\boldsymbol{\Delta}) \mathrm{N}$ inputs respectively. Map by Anette Th. Meier.

extends the focus to also involve phosphorus (P), which the seabirds also bring into the ecosystem (Aerts et al. 2020). No study has, however, so far looked at the other macro- and micro-nutrients in the Surtsey ecosystems and compared those to the autonomous soil development of the older islands in the Vestmannaeyjar archipelago.

The present study was performed in 2013, when the impact of seabird presence and soil age on soil nutritional availability were studied by incubating resin membranes charged with either anions or cations in the soils of Surtsey (50 years old) and of Heimaey and Elliðaey (ca. 5900 years old). Sampling was performed both inside and outside the seabird colonies on the young and older islands, as well as on both shallow soils formed on lava surfaces and on deeper soils formed in tephra (volcanic ash) deposited during the eruption on Surtsey. The aims were (1) to get a deeper understanding of the nutrient cycle on Surtsey and on potentially limiting nutrients there and (2) to study potential build-up of heavy metals $(\mathrm{Cd}$ and $\mathrm{Pb})$ within the seabird colonies.

\section{MATERIAL AND METHODS}

Study area

The study was performed on three islands of the volcanic Vestmannaeyjar archipelago $\left(63^{\circ} 250 \mathrm{~N}\right.$, $20^{\circ} 170 \mathrm{~W}$; south Iceland; Fig. 1) in mid-July 2013. The main vegetation type on the Vestmannaeyjar archipelago is lush grassland, except in areas that are unsuitable for seabird colonization, where heathlands, herb slopes or dry meadows can be found (Magnússon et al. 2014). Two pairs of sites with low and high natural seabird inputs were established, one pair with high seabird inputs on Surtsey and Elliðaey and another pair with low seabird inputs at Surtsey and Heimaey (Fig. 1). At Surtsey the soils were at an early developmental stage (50 years old), but both Heimaey (Lyngfellisdalur) and Elliðaey have well-developed soils on bedrocks that both date from eruptions ca. 5900 years ago. The soil profiles at Heimaey and Elliðaey were undisturbed at least since $395 \mathrm{AD}$, which was determined from the precence of an ash layer from that time $>1 \mathrm{~m}$ below the surface (Leblans et al. 2017). Both the Surtsey and the Heimaey and Elliðaey sites have 
Table 1. Distribution of the treatments over the plots used in the study and their dominant plant species.

\begin{tabular}{|c|c|c|}
\hline Islands and experimental category & Plot numbers & Dominant plant species \\
\hline \multicolumn{3}{|l|}{ Elliðaey } \\
\hline Deep, + seabirds & $1,2,3,4$ & Festuca richardsonii, Poa sp., Stellaria media \\
\hline \multicolumn{3}{|l|}{ Heimaey } \\
\hline Deep, no sesbirds & $1,2,3,4$ & Anthoxantum odoratum, Galium verum, Luzula multiflora \\
\hline \multicolumn{3}{|l|}{ Surtsey } \\
\hline Shallow, no seabirds & $16,18,19,22$ & Leymus arenarius, Honckenya peploides \\
\hline Shallow, + seabirds & $6,7,9,23$ & Festuca richardsonii, Poa sp., Pucinellia capillaris. \\
\hline Deep, no seabirds & $11,13,14,20,30$ & Leymus arenarius, Honckenya peploides \\
\hline Deep, + seabirds & $1 *, 3,4$ & Leymus arenarius, Poa sp., Stellaria media \\
\hline
\end{tabular}

* Excluded for macro-nutrients

different vegetation communites, which represent the differences in seabird influence (Magnússon et al. 2014). The Heimaey site is not likely to ever have hosted a seabird colony because of its topographic position, while Elliðaey has topographical conditions that make it highly likely that the island has served as breeding ground for seabirds from early times. The study took place in four permanent 10x10 m study plots that were established at Heimaey and Elliðaey in 2013. These are the same plots that were included in Magnusson et al. (2014) and Leblans et al. (2017) studies that confirmed the long-term $\mathrm{N}$-accumulation and the contrasting seabird influences at these sites. The vegetation on Elliðaey, which had deep soils with seabird inputs, was similar as in Surtsey, with Festuca richardsonii, Poa sp., Stellaria media as dominant plant species. On Heimaey, which had deep soils without seabird influcecs, the vascular plant community was dominated by Anthoxantum odoratum L., Galium verum L., Luzula multiflora (Ehrh.) Lej.; a herb rich grassland community of low fertility (Magnusson et al. 2014) (Table 1).

At Surtsey, the study was conducted in a series of permanent plots that were already established between 1990 and 1995 (Fig. 1), both inside and outside the seagull breeding colony. The seagull colony was originally established in 1986 on the south-western part of the island and by time it has grown in size as the number of birds has increased (Leblans et al. 2014). In Surtsey, the plots inside and outside the colony were further divided into plots with shallow soils $(\leq 10 \mathrm{~cm}$ soil) formed by windborne tephra sands that had covered the basaltic lava surfaces and plots with deep soils ( $>30 \mathrm{~cm}$ soil) in areas where the tephra sands had been deposited during the eruption (see Leblans et al. 2014 for further details). The vegetation on the sandy areas outside the colony on Surtsey was dominated by Honckenya peploides (L.) Ehrh. and Leymus arenarius (L.) Hochst. The dominant plant species inside the seagull colony were Poa pratensis L., P. annua L., Festuca richardsonii (Hook.) Hultén., with some Leymus arenarius and Stellaria media (L.) Vill. in deep soils (Table 1). In the area many other studies have already taken place (c.f. Magnusson et al. 2014, Leblans et al. 2014, 2017, Aerts et al. 2020).

\section{Sampling}

Soil depth was measured using a $1.2 \mathrm{~m}$ long metallic rod pushed down until hitting a rock at 11 places along the $\mathrm{S}$ edge of each permanent plot, but recorded as $1.5 \mathrm{~m}$ when deeper.

A relative measure for nutrient and pollutant availability was obtained using cation- and anionexchange membranes (PRSTM probes, Western Ag Innovations Inc.; Saskatoon, SK, Canada). The membranes continuously absorb charged ionic species over the burial period, and the ion availability is calculated as soil flux of exchangable ions. Four sets of cation and anion PRS ${ }^{\mathrm{TM}}$ membranes were inserted into the topsoil $(0-10 \mathrm{~cm}$ depth $)$ at each main study plot in mid-July 2013; 15 - 21 July on Surtsey and $19-24$ and $19-27$ July on Heimaey and Elliðaey, respectively. Afterwards, they were sent to Western Ag Innovations Inc. (Saskatoon, SK, Canada) for further analyses.

\section{Data and statistical analyses}

Plots where either all PRS ${ }^{\mathrm{TM}}$ anion or cation membranes were lost during the incubation period were not included in the analysis. These were two plots on Surtsey, R21 and R8. The reason for the loss 
of membranes was that seagulls had dragged them out of the soil. One plot, R1, was excluded from the analysis of macro-nutrients on Surtsey as the values were extremely high (10-100 $\mathrm{x}$ higher than anywhere else). There was a major dieback of Poa annua in this plot following a prolonged drought during summer of 2012, a year before this study took place, which has since then resulted in rapid species turnover and a large increase in Stellaria media cover (unpublished data). The plot was therefore an "outlier" for the Surtsey seagull colony as a whole. Further, few samples for the nutrients NO3-N and NH4-N did not quite meet the method detection limits (MDL) of PRSTM which is $2 \mathrm{mg} \mathrm{N} / 10 \mathrm{~cm}^{2}$, but were still included in the analysis. Similarly, not all $\mathrm{Mn}$ and $\mathrm{Cu}$ concentrations reached the MDL of $0.2 \mathrm{mg} / 10 \mathrm{~cm}^{2}$, but were still included. Finally, $\mathrm{Pb}$ and $\mathrm{Cd}$ pollutant concentrations never reached the given MDL of 0.2 $\mathrm{mg} / 10 \mathrm{~cm}^{2}$.

The effets of the chronically elevated seabird inputs and soil age on nutrient and pollutant availability were tested with a two-way ANOVA, with sebird input (low/high) and soil age (young/old) as fixed factors. In case of significant interaction, the pairwise differences were tested by post hoc LSD tests when the requirements of normality and homoscedasticity of the residuals were met. The latter was visually inspected.

\section{RESULTS AND DISCUSSION}

\section{Macro-nutrients}

Total mineral N, NO3-N and NO4-N in the topsoil and all the other macro-elements were significantly increased by the seabird precence, both at Surtsey and on the older islands (Fig. 2; Table 2). The significant interaction for both total mineral $\mathrm{N}$ and NO3-N seen in Table 2 was caused by the relatively stronger increase on the older islands compared to Surtsey (Fig. 2). The seabird-driven increase in total mineral $\mathrm{N}$ was 11-fold on the old isands, while it was only 4-fold on Surtsey. For NO3-N this increase was 36-fold and 3-fold, repectively. Leblans et al. (2017) have shown that the seabird $\mathrm{N}$-inputs are somewhat higher within the seabird colony on Elliðaey than on Surtsey, ca. 67 versus $47 \mathrm{~kg} \mathrm{~N} /$ ha /year, compared to ca. $1-2 \mathrm{~kg} \mathrm{~kg} \mathrm{~N} / \mathrm{ha} /$ year background atmospheric $\mathrm{N}$-deposition. The relatively lower seabird response of the total mineral $\mathrm{N}$ availability in the topsoil on the younger Surtsey can possibly be explained by the much smaller total soil $\mathrm{N}$ stock that has accumulated

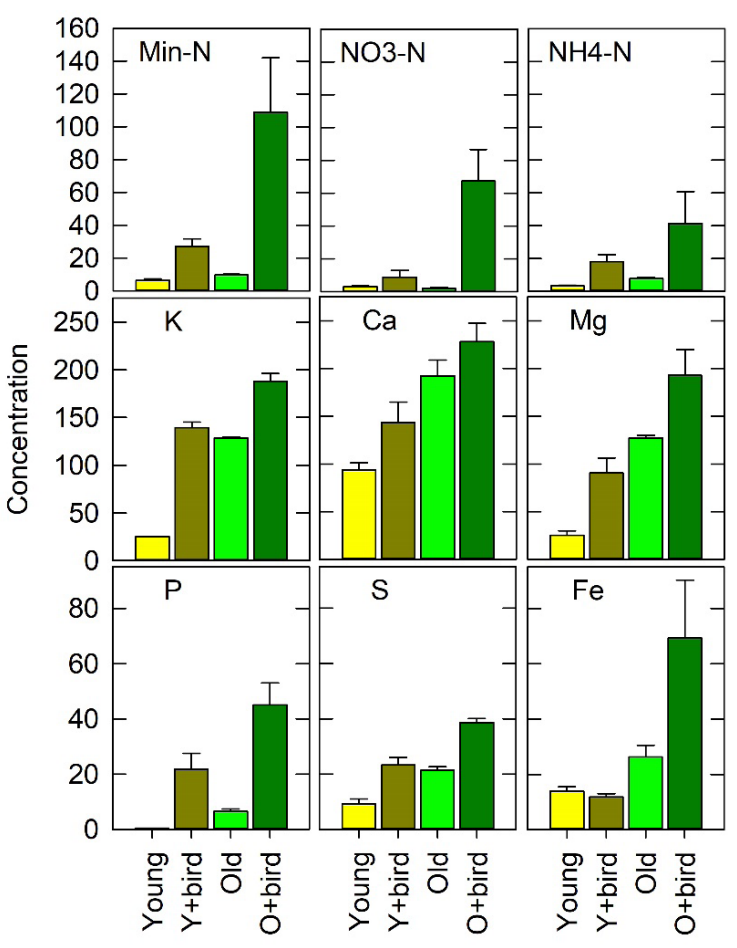

Figure 2. Availability of various macro elements and iron (Fe) after 5-8 day incubation of PRS ${ }^{\mathrm{TM}}$ resin probes in $0-10 \mathrm{~cm}$ soil depth, or laterally where the soil was thinner, in permanent plots on islands of varying age (Young: Surtsey $=50$ years; Old: Heimaey/Elliðaey = ca. 5900 years) in areas with seabird presence (+bird) or not. The unit is $\mathrm{mg}$ ion $/ 10 \mathrm{~cm}^{2}$ resin membrane. Bars show plot means $\pm \mathrm{SE}$ of $\mathrm{n}=2-5$. Note the different scales on the y-axes. See Table 1 for plot numbers in each category and Table 2 for statistical analysis.

there (Leblans et al. 2017). This lower stock could lead to a relatively higher $\mathrm{N}$ uptake by plants on Surtsey in the most active growing season in July (cf. Aerts et al. 2020).

The older islands had a significantly higher availability of all macro-nutrients (Table 2; Island age effect) except for NH4-N, which was not significant when compared across all plots (Fig. 2). The NO3-N ratio in the total mineral $\mathrm{N}$ was higest $(62 \%)$ within the very fertile seabird colony on Elliðaey, but lower in the more infertile grassland soil on Heimaey (19\%) and on Surtsey (37\% across all plots; Table 3 ).

Macro-nutrient cation availability $(\mathrm{Ca}, \mathrm{K}, \mathrm{Mg})$ was very high compared to N, P and S (Figure 2; note the different scales on $\mathrm{y}$-axes). This is typical for young basaltic substrates in Iceland (Arnalds 2015). Outside the seabird colony on Surtsey the availability of those cations was significantly lower than within the seabird colony, except for $\mathrm{Ca}$ that did not vary 
Table 2. Statistical results (p-values) of 2-way analyses of variance on the availability of various elements as a function of seabird presence and island age as independent parameters in Surtsey, Heimay and Elliðaey, as shown in Figures 2-4. Bold font indicates significant differences ( $p$ $<0.05)$.

\begin{tabular}{lrrr}
\hline & $\begin{array}{c}\text { Seabird } \\
\text { presence }\end{array}$ & Island age & $\begin{array}{r}\text { Inter- } \\
\text { action }\end{array}$ \\
\hline Macro-nutients & & & \\
$\mathrm{NO} 3-\mathrm{N}$ & $<\mathbf{0 . 0 0 1}$ & $<\mathbf{0 . 0 0 1}$ & $<\mathbf{0 . 0 0 1}$ \\
$\mathrm{NH} 4-\mathrm{N}$ & $\mathbf{0 . 0 0 3}$ & 0.07 & 0.21 \\
Mineral-N & $<\mathbf{0 . 0 0 1}$ & $\mathbf{0 . 0 0 2}$ & $\mathbf{0 . 0 0 4}$ \\
$\mathrm{P}$ & $<\mathbf{0 . 0 0 1}$ & $\mathbf{0 . 0 0 4}$ & 0.07 \\
$\mathrm{~K}$ & $\mathbf{0 . 0 0 3}$ & $\mathbf{0 . 0 0 7}$ & 0.30 \\
$\mathrm{Mg}$ & $<\mathbf{0 . 0 0 1}$ & $<\mathbf{0 . 0 0 1}$ & 0.99 \\
$\mathrm{Ca}$ & $\mathbf{0 . 0 2}$ & $<\mathbf{0 . 0 0 1}$ & 0.68 \\
$\mathrm{~S}$ & $<\mathbf{0 . 0 0 1}$ & $<\mathbf{0 . 0 0 1}$ & 0.44 \\
$\mathrm{Micro}-$-nutrients & & & \\
$\mathrm{Fe}$ & $\mathbf{0 . 0 1}$ & $<\mathbf{0 . 0 0 1}$ & $\mathbf{0 . 0 0 6}$ \\
$\mathrm{Mn}$ & $\mathbf{0 . 0 0 1}$ & $<\mathbf{0 . 0 0 1}$ & 0.15 \\
$\mathrm{Cu}$ & 0.06 & $<\mathbf{0 . 0 0 1}$ & 0.82 \\
$\mathrm{Zn}$ & $\mathbf{0 . 0 1}$ & $\mathbf{0 . 0 2}$ & $\mathbf{0 . 0 0 1}$ \\
$\mathrm{B}$ & 0.90 & 0.66 & 0.98 \\
Aluminum and pollutants & & \\
$\mathrm{Al}$ & 0.45 & $<\mathbf{0 . 0 0 1}$ & 0.94 \\
$\mathrm{Cd}$ & 0.25 & $\mathbf{0 . 0 0 9}$ & 0.80 \\
$\mathrm{~Pb}$ & 0.90 & $\mathbf{0 . 0 0 8}$ & 0.66 \\
\hline
\end{tabular}

across different plots on Surtsey (Tables 3 and 4). This does not necessarily mean that those extra cations are seabird-borne; they can also accumulate due to more root-growth activity, SOM build-up and decompositon (soil respiration) following primary succession within the seabird colony (Sigurdsson 2015, Sigurdsson \& Magnusson 2010, Leblans et al. 2014, 2017).

Some of the soils on Surtsey are very thin (or 4-6 $\mathrm{cm}$; Table 3), on top of a basaltic lava bedrock. A tendency for higher average cation availability was seen in plots with the thin soils on Surtsey (Table 3 and 4), but it was only signifcant for Mg. This is the same effect as reported by Aerts et al. (2020) for $\mathrm{N}$ and $\mathrm{P}$ and probably indicates more root-mediated dilution in the deeper tephra soils.

The $P$ availability was significantly enhanced by the seabird presence, irrespective of island age, and it was also on average significantly higher in the older soils (Fig.2; Table 2). Aerts et al. (2020) found with isotopic analyses that most of the $\mathrm{P}$ in the seabird colony of Surtsey was derived from the seagulls. They also found indications from N/P stociometry of plant biomass that $\mathrm{P}$ could possibly be co-limiting outside the seagull colony in Surtsey. This is, however, not supported by Leblans et al. (2017) stociometery of Cerastium fontanum plants growing in or close to all permanent plots on Surtsey. A non-molar corrected $\mathrm{P} / \mathrm{N}$ ratio of 0.08 is needed to maintain optimum growth in plants (Linder \& Ingestad 1977, Sigurdsson 2001). It is noteworthy that outside the seagull colony at Surtsey the ratio between $\mathrm{P}$ and mineral-N availability was exactly 0.08 in the $3-6$ $\mathrm{cm}$ thin soils, but only 0.06 in the topsoil layer of the deeper soils (Table 3). However, this analysis does not include organic $\mathrm{P}$ and $\mathrm{N}$ that vascular plants can get from symbiotic mycorrhyzal fungi (Chapin et al. 2002) and deep-rooted plants may have accessed additional P-stores from below the topsoil. The role of $\mathrm{P}$ in the funcitoning of the plant communities outside the seagull colony in Surtsey is therefore still an open question and warrants a futher study.

Sulfur (S) availability also increased significantly both with seabird presence and island age (Fig. 2; Table 2). It had a slight, but significant reduction in topsoil of deeper tephra soils in Surtsey (Tables 3 and 4). Its availability was in a similar range as $P$ on all isands with seabird influence ( $\mathrm{S} / \mathrm{P}$ ratio of $0.9-1.1$ ). The S/P ratio was ca. 3 on Heimaey and as high as 21 outside the seabird colony on Surtsey (Fig. 2). It is therefore unlikely that $\mathrm{S}$ will become a limiting nutrient in those island ecosystems compared to $\mathrm{N}$ or $\mathrm{P}$, since plants require only ca. half as much $\mathrm{S}$ as $\mathrm{P}$ for maintaining optimum growth rates (Linder \& Ingestad 1977).

\section{Micro-nutrients}

The availability of Fe was very high on all islands (Fig. 2), but was only signifcantly increased by seabird precense on the old islands; hence the signicant interaction term in Table 2. Availability of $\mathrm{Zn}$ was ca. $1 / 10$ of the $\mathrm{Fe}$, and it had an unexpected spatial trend with the highest availability within the seagull colony on Surtsey, but similar and lower values elsewhere. This also explains the significant interaciton term in Table 2. The relatively high availability of $\mathrm{Zn}$ compared to e.g. minearal N (Figs. 2 and 3), with $\mathrm{Zn} / \mathrm{N}$ ratio of ca. 0.1 on Surtsey and Heimaey, makes it unlikely that $\mathrm{Zn}$ plays any important role in the biogeochemistry of the island ecosystems. The $\mathrm{Zn} / \mathrm{N}$ ratio of 0.0005 are enough to maintain optimum growth of plants (Linder \& Ingestad 1977). Similarly Mn values were relatively high (Fig. 3), the lowest $\mathrm{Mn}$ values were found outside the seagull colony 


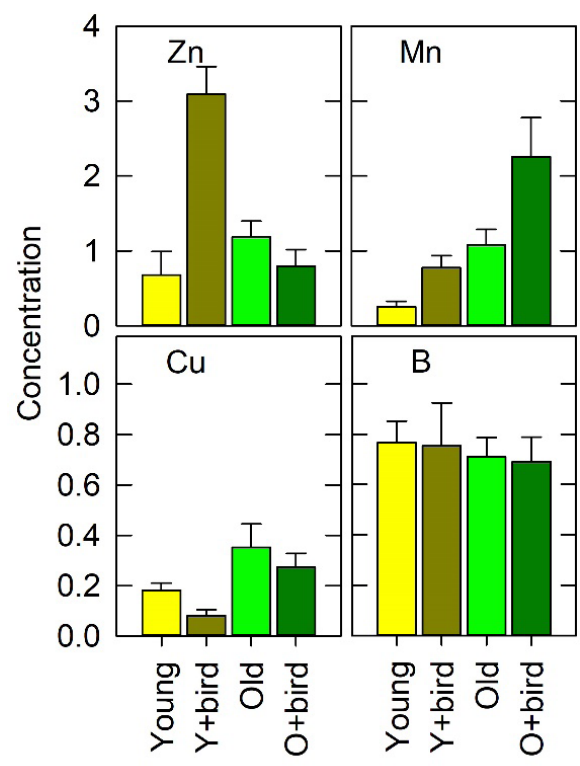

Figure 3. Availability of various micro elements after 5-8 day incubation of PRS ${ }^{\mathrm{TM}}$ resin probes in $0-10 \mathrm{~cm}$ soil depth, or laterally where the soil was thinner, in permanent plots on islands of varying age (Young: Surtsey $=50$ years; Old: Heimaey/ Elliðaey $=$ ca. 5900 years) in areas with seabird presence $(+$ bird $)$ or not. The unit is $\mathrm{mg}$ ion $/ 10 \mathrm{~cm}^{2}$ resin membrane. Bars show plot means \pm SE of $n=3-5$. Note the different scales on the $y$-axes. See Table 1 for plot numbers in each category and Table 2 for statistical analysis.

on Surtsey, but still the $\mathrm{Mn} / \mathrm{N}$ ratio there was ca. 0.04, which is two orders of magnitude higher than needed to maintain optimum plant growth (Linder \& Ingestad 1977). Further, the Mn availability increased significantly both with seabird persence and island age (Table 2), but not with soil depth on Surtsey (Tables 3 and 4).

The $\mathrm{Mn} / \mathrm{N}$ ratio was highest outside the seagull colony on Surtsey (0.12), but lowest on Elliðaey (0.006) (Figs 2 and 3). According to Linder \& Ingestad (1977) a Mn:N ratio of 0.0005 is more than enough for optimum growth of vascular plants; hence the $\mathrm{B}$ availability compared to mineral $\mathrm{N}$ was still an order of magnitude higher than needed.

The two micro-nutrients with by far the lowest availability in the present study were $\mathrm{B}$ and $\mathrm{Cu}$ (Fig. 3 ). The B availability did not change significantly with seabird presence or age of soil (Table 2) nor by soil depth on Surtsey (Table 3). On average it was $0.74 \pm 0.06 \mathrm{mg} \mathrm{B} / 10 \mathrm{~cm}^{2}$.

Copper was the micro-nutrient with the lowest availability in the present study. Something that has also been found in foilage analysis of plants growing on Brown Andosols on mainland Iceland (Sigurdsson 2001). Its availability increased significantly with seabird presence (and plant succession) on Surtsey (Tables 3 and 4), but not overall on the islands (Fig. 3; Table 2). However, it did increase significantly with soil age across both the older islands (Fig. 3; Table 2). $\mathrm{Cu}$ is the micro-nutreint included in the present study that plants need least amounts of, or less than 0.0003 $\mathrm{Cu} / \mathrm{N}$ ratio (Linder \& Ingestad 1977). The $\mathrm{Cu} / \mathrm{N}$ ratio in the seabirds colonies of Surtsey and Elliðaey was ca. 0.003, while it was order of magnitude larger without the seabird presence (ca. 0.03). Hence, $\mathrm{Cu}$ seems not to be a limiting element compared to $\mathrm{N}$ and possibly $\mathrm{P}$, according to its soil availability found in the present study.

\section{Aluminium and pollutants}

The soils in the present study were Al rich (Fig. 4), which is normal for volcanic soils (Arnalds, 2015). The Al availability did not decrease with soil age, but increased significantly which indicates a higher bedrock weathering activity than $\mathrm{Al}$ leaching (Fig. 4; Table 2). Further, Al did not vary with soil depth on Surtsey (Tables 3 and 4). An expected increase in the solubility of Al in the more acid soils within the seabird colonies (Sigurdsson \& Magnússon 2010, Leblans et al. 2017) was not observed. The 5-7 times higher availability of the other cations in the island soils could effectively have buffered that response, as they would be pushed out of the exchange sites before Al.

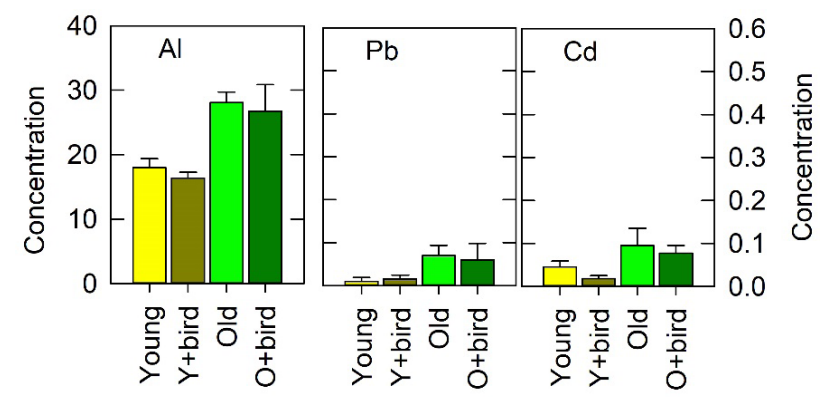

Figure 4. Availability of aluminium and pollutants after 5-8 day incubation of PRS ${ }^{\mathrm{TM}}$ resin probes in $0-10 \mathrm{~cm}$ soil depth, or laterally where the soil was thinner, in permanent plots on islands of varying age (Young: Surtsey $=50$ years; Old: Heimaey/Elliðaey $=$ ca. 5900 years) in areas with seabird presence (+bird) or not, as independent parameters. The unit is $\mathrm{mg}$ ion $/ 10 \mathrm{~cm}^{2}$ resin membrane $/ 5$ days. Bars show plot means $\pm \mathrm{SE}$ of $n=3-5$. Note the different scales on the y-axes. See Table 1 for plot numbers in each category and Table 2 for statistical analysis. 
Table 3. Soil depth and the availability of various elements after six days incubation of PRSTM resin probes in $0-10 \mathrm{~cm}$ soil depth on Surtsey. The unit is $\mathrm{mg}$ ion $/ 10 \mathrm{~cm} 2$ resin membrane. Numbers are plot means \pm SE of $\mathrm{n}=2-5$. See Table 1 for plot numbers in each category and Table 4 for statistical analysis.

\begin{tabular}{|c|c|c|c|c|}
\hline & \multicolumn{2}{|l|}{ Outside } & \multicolumn{2}{|l|}{ Seabirds } \\
\hline & Shallow & Deep & Shallow & Deep \\
\hline Soil depth & $3.7 \pm 2.1$ & $100.0 \pm 21.9$ & $6.2 \pm 2.8$ & $39.4 \pm 9.8$ \\
\hline \multicolumn{5}{|c|}{ Macro-nutrients } \\
\hline NO3-N & $2.3 \pm 0.8$ & $3.7 \pm 1.4$ & $10.5 \pm 4.3$ & $5.8 \pm 1.0$ \\
\hline NH4-N & $3.7 \pm 0.7$ & $3.0 \pm 0.7$ & $16.8 \pm 5.1$ & $21.0 \pm 9.1$ \\
\hline Mineral-N & $6.0 \pm 1.2$ & $6.7 \pm 1.5$ & $27.2 \pm 6.0$ & $26.8 \pm 10.1$ \\
\hline $\mathrm{P}$ & $0.5 \pm 0.1$ & $0.4 \pm 0.1$ & $25.8 \pm 9.0$ & $13.8 \pm 1.0$ \\
\hline K & $32.9 \pm 20.4$ & $19.5 \pm 2.3$ & $152.5 \pm 36.0$ & $113.1 \pm 9.0$ \\
\hline $\mathrm{Mg}$ & $30.4 \pm 10.6$ & $21.1 \pm 4.1$ & $107.8 \pm 20.3$ & $56.1 \pm 5.7$ \\
\hline $\mathrm{Ca}$ & $92.9 \pm 15.0$ & $94.0 \pm 10.6$ & $154.1 \pm 35.0$ & $122.2 \pm 0.4$ \\
\hline $\mathrm{S}$ & $9.9 \pm 4.7$ & $8.5 \pm 1.6$ & $24.0 \pm 4.5$ & $22.3 \pm 3.4$ \\
\hline \multicolumn{5}{|c|}{ Micro-nutrients } \\
\hline $\mathrm{Fe}$ & $13.9 \pm 4.2$ & $13.9 \pm 1.1$ & $12.0 \pm 2.3$ & $11.5 \pm 0.9$ \\
\hline $\mathrm{Mn}$ & $0.3 \pm 0.2$ & $0.2 \pm 0.0$ & $0.9 \pm 0.3$ & $0.6 \pm 0.1$ \\
\hline $\mathrm{Zn}$ & $1.0 \pm 0.8$ & $0.4 \pm 0.1$ & $3.5 \pm 0.6$ & $2.6 \pm 0.3$ \\
\hline $\mathrm{Cu}$ & $0.2 \pm 0.1$ & $0.2 \pm 0.0$ & $0.1 \pm 0.0$ & $0.1 \pm 0.0$ \\
\hline B & $0.7 \pm 0.2$ & $0.8 \pm 0.1$ & $0.9 \pm 0.3$ & $0.5 \pm 0.1$ \\
\hline \multicolumn{5}{|c|}{ Aluminium and pollutants } \\
\hline $\mathrm{Al}$ & $16.4 \pm 2.8$ & $19.3 \pm 1.5$ & $16.8 \pm 1.3$ & $15.9 \pm 1.4$ \\
\hline $\mathrm{Cd}$ & $0.05 \pm 0.03$ & $0.05 \pm 0.02$ & $0.02 \pm 0.01$ & $0.01 \pm 0.01$ \\
\hline $\mathrm{Pb}$ & $0.02 \pm 0.02$ & $0.00 \pm 0.00$ & $0.01 \pm 0.01$ & $0.02 \pm 0.02$ \\
\hline
\end{tabular}

Table 4. Statistical results ( $p$-values) of 2-way analyses of variance on the availability of various elements on Surtsey, as shown in Table 3. Bold font indicates significant differences $(\mathrm{p}<0.05)$.

\begin{tabular}{lrcc}
\hline & $\begin{array}{c}\text { Seabird } \\
\text { presence }\end{array}$ & $\begin{array}{l}\text { Soil } \\
\text { depth }\end{array}$ & $\begin{array}{c}\text { Inter- } \\
\text { action }\end{array}$ \\
\hline Soil depth & 0.08 & $\mathbf{0 . 0 0 1}$ & 0.06 \\
Macro-nutients & & & \\
NO3-N & 0.09 & 0.57 & 0.29 \\
$\mathrm{NH} 4-\mathrm{N}$ & $\mathbf{0 . 0 0 2}$ & 0.66 & 0.54 \\
Mineral-N & $<\mathbf{0 . 0 0 1}$ & 0.97 & 0.91 \\
$\mathrm{P}$ & $\mathbf{0 . 0 0 3}$ & 0.27 & 0.28 \\
$\mathrm{~K}$ & $<\mathbf{0 . 0 0 1}$ & 0.28 & 0.59 \\
$\mathrm{Mg}$ & $\mathbf{0 . 0 0 1}$ & $\mathbf{0 . 0 4}$ & 0.14 \\
$\mathrm{Ca}$ & 0.08 & 0.51 & 0.48 \\
$\mathrm{~S}$ & $<\mathbf{0 . 0 0 1}$ & $<\mathbf{0 . 0 0 1}$ & 0.44 \\
Micro-nutrients & & & \\
$\mathrm{Fe}$ & 0.38 & 0.90 & 0.92 \\
$\mathrm{Mn}$ & $\mathbf{0 . 0 1}$ & 0.42 & 0.53 \\
$\mathrm{Cu}$ & $\mathbf{0 . 0 2}$ & 0.37 & 0.41 \\
$\mathrm{Zn}$ & $<\mathbf{0 . 0 0 1}$ & 0.14 & 0.73 \\
$\mathrm{~B}$ & 0.83 & 0.40 & 0.14 \\
Aluminum and pollutants & & & \\
$\mathrm{Al}$ & 0.41 & 0.57 & 0.30 \\
$\mathrm{Cd}$ & 0.14 & 0.82 & 0.77 \\
$\mathrm{~Pb}$ & 0.70 & 0.70 & 0.35 \\
\hline
\end{tabular}

The pollutants $\mathrm{Cd}$ and $\mathrm{Pd}$ were found with an extremely low availability in the present study and were in fact below the given MDL of $0.2 \mathrm{mg} / 10 \mathrm{~cm}^{2}$. Still the membranes yielded some ions, but only on average 0.05 and $0.02 \mathrm{mg} / 10 \mathrm{~cm}^{2}$, across all plots, respectively. Since the measurements are so much lower than the MDL of the method, these results are an indication rather than a confirmation of the extremely low values. Both metals can accumulate in oceanic food webs (Kay 1985, Michaels \& Flegal 1990). It was therefore of interest if we would find increased accumulation in areas with large seabird presence, which was not the case (Fig. 3; Tables 2-4). However, both metals showed a significant increase in availability with soil age (Table 2). Even then, they only reached ca. half of the MDL for $\mathrm{Cd}$ and $\mathrm{Pb}$, so we can conclude that both are very low.

\section{Conclusion}

The present study was the first on the availability of most soil macro- and micro-nutrients on Surtsey and the older islands in the Vestmannaeyjar archepelago. The findings support that $\mathrm{N}$ is generally the most limiting plant nutrient in these ecosystems. However, in the young, undeveloped soils outside the seagull colonies on Surtsey, P availability could possibly 
reach co-limitation as $\mathrm{N}$ has accumulated by $1-2 \mathrm{~kg}$ $\mathrm{N} /$ ha / year from atmospheric deposition during the last 50 years (Stefánsdóttir et al. 2014). The role of $\mathrm{P}$ in ecosystem function hence warrants a futher study on Surtsey.

\section{ACKNOWLEDGEMENTS}

The authors would like to thank Dr Borgpór Magnússon, Icelandic Institute of Natural History, for coordinating the Surtsey excursion in 2013, the Surtsey Research Society for permitting this study and Pórdís Bragadóttir and Hekla Hrund Bjarnadóttir for help during fieldwork.

\section{REFERENCES}

Aerts, R., R.S.P. van Logtestijn, N.I.W. Leblans \& B.D. Sigurdsson, 2020. Effects of sea birds and soil development on plant- and soil-nutritional parameters after 50 years of succession on Surtsey. Surtsey Research 14, 85-90.

Arnalds, O., 2015. The soils of Iceland. Springer, Netherlands.

Chapin III, F.S., P.A. Matson \& H.A. Mooney, 2002. Principles of terrestrial ecosystem ecology. Springer: New York, Berlin, London.

Ilieva-Makulec, K., B. Bjarnadottir \& B.D. Sigurdsson, 2015. Soil nematode communities on Surtsey, 50 years after the formation of the volcanic island. Icelandic Agricultural Sciences 28, 43-58.

Kay S.H., 1985. Cadmium in aquatic food webs. In Gunther F.A. (eds) Residue Reviews. Residue Reviews, vol 96. Springer, New York, NY.

Leblans, N.I.W., B.D. Sigurdsson, P. Roefs, R. Thuys, B. Magnusson, \& I.A. Janssens, 2014. Effects of seabird nitrogen input on biomass and carbon accumulation after 50 years of primary succession on a young volcanic island, Surtsey. Biogeosciences 11, 6237-6250.

Leblans, N.I.W., B.D. Sigurdsson, R. Aerts, S. Vicca, B. Magnússon \& I.A. Janssens, 2017. Icelandic grasslands as long-term $\mathrm{C}$ sinks under elevated organic $\mathrm{N}$ inputs. Biogeochemistry 134, 279-299.

Linder, S. \& T. Ingestad, 1977. Ecophysiological experiments under limiting and non-limiting conditions of mineral nutrition in field and laboratory. In Bicentenary celebration of C.P. Thunberg's visit to Japan, The Botanical Society of Japan, Tokyo, pp. 69-76.

Magnússon B., S.H. Magnússon, E. Ólafsson \& B.D. Sigurdsson, 2014. Plant colonization, succession and ecosystem development on Surtsey with reference to neighbour islands. Biogeosciences 11, 5521-5537.

Marteinsson, V., A. Klonowski, E. Reynisson, P. Vannier, B.D. Sigurdsson \& M. Ólafsson, 2015. Microbial colonization in diverse surface soil types in Surtsey and diversity analysis of its subsurface microbiota. Biogeosciences 12, 1-13.

Michaels A.F. \& A.R. Flegal, 1990. Lead in marine planktonic organisms and pelagic food webs. Limnol. Oceanogr 35 (2), 282-295.

Sigurdsson, B.D., 2001. Environmental control of carbon uptake and growth in a Populus trichocarpa plantation in Iceland. PhD thesis. Swedish University of Agricultural Sciences: Uppsala, Sweden, 64 p.

Sigurdsson, B.D. \& G. Stefánsdóttir, 2015. Ecosystem $\mathrm{CO}_{2}$ flux rates in relaton to vegetation type and age of Leymus arenarius dunes on Surtsey. Surtsey Research 13, 9-15.

Sigurdsson, B.D. \& B. Magnusson, 2010. Ecosystem respiration, vegetation development and soil nitrogen in relation to breeding density of seagulls on a pristine volcanic island, Surtsey, Iceland. Biogeosciences 7, 883-891.

Stefansdottir, G., A.L. Aradottir \& B.D. Sigurdsson, 2014. Accumulation of nitrogen and organic matter during primary succession of Leymus arenarius dunes on the volcanic island Surtsey, Iceland. Biogeosciences 11, 5763-5771.

Walker, L. R. \& R. Del Moral, 2003. Primary succession and ecosystem rehabilitation, Cambridge University Press, Cambridge. 